\title{
DEVELOPMENT OF VACCINES AND PASSIVE IMMUNOTHERAPY AGAINST SARS CORONAVIRUS USING MOUSE AND SCID-PBL/hu MOUSE MODELS
}

Masaji Okada, Yuji Takemoto, Yoshinobu Okuno, Satomi Hashimoto, Yukari Fukunaga, Takao Tanaka, Yoko Kita, Sechiko Kuwayama, Yumiko Muraki, Noriko Kanamaru, Hiroko Takai, Chika Okada, Yayoi Sakaguchi, Izumi Furukawa, Kyoko Yamada, Miwa Izumiya, Shigeto Yoshida, Makoto Matsumoto, Tetsuo Kase, J. S. M. Peiris, Daphne E. deMello, Pei-Jer Chen, Naoki Yamamoto, Yoshiyuki Yoshinaka, Tatsuji Nomura, Isao Ishida, Shigeru Morikawa, Masato Tashiro, and Mitsunori Sakatani*

\footnotetext{
*Masaji Okada, Yuji Takemoto, Satomi Hashimoto, Yukari Fukunaga, Takao Tanaka, Yoko Kita, Sachiko Kuwayama, Yumiko Muraki, Noriko Kanamaru, Hiroko Takai, Chika Okada, Yayoi Sakaguchi, Izumi Furukawa, Kyoko Yamada, Miwa Izumiya, Mitsunori Sakatani, Clinical Research Center, National Hospital Organization Kinki-Chuo Chest Medical Center, Sakai, Osaka, 591-8555, Japan. Yoshinobu Okuno, Tetsuo Kase, Department of Infectious Diseases, Osaka Prefectural Institute of Public Health, Higashinari-ku, Osaka, 537-0025, Japan. Shigeto Yoshida, Department of Infection and Immunity, Jichi Medical School, Minamikawachi-machi, Tochigi, 329-0498, Japan. Makoto Matsumoto, Microbiological Research Institute, Otsuka Pharmaceutical Co., Ltd., Tokushima, 771-019, Japan. J. S. M. Peiris, Department of Microbiology, The University of Hong Kong, Pokfulam Road, Hong Kong. Daphne E. deMello, Department of Pathology Cardinal Glennon Children's Hospital, St. Louis Univ. Health Science Center, St. Louis, MO 63104, USA. Pei-Jer Chen, Hapatitis Research Center, National Taiwan University College of Medicine, Taipei, Taiwan. Naoki Yamamoto, Yoshiyuki Yoshinaka, Tokyo Medical and Dental University, Bunkyo-ku, Tokyo 113-8549, Japan. Tatsuji Nomura, Central Institute for Experimental Animals, Kawasaki, Kanagawa, 216-0001, Japan. Isao Ishida, Pharmaceutical Division, Kirin Brewery Co., Shibuya, Tokyo, 150-8011, Japan. Shigeru Morikawa, Masato Tashiro, National Institute of Infectious Diseases, Tokyo, Shinjuku-ku, Tokyo 162-8640, Japan.
} 


\section{ABSTRACT}

We have investigated novel vaccines strategies against severe acute respiratory syndrome (SARS) CoV infection using cDNA constructs encoding the structural antigens; spike (S), membrane (M), envelope (E), or nucleocapsid (N) protein, derived from SARS CoV (strain HKU39849, TW1, or FFM-1). As SARS-CoV is thought to infect the alveolar epithelial cell of the lung,in the present study, a type II alveolar epithelial cell clone, T7, was used to analyze the mechanism of CTL against SARS CoV membrane antigens. Mice vaccinated with SARS CoV (N) DNA or (M) DNA using pcDNA 3.1(+) plasmid vector showed T-cell immune responses (CTL induction and proliferation) against type II alveolar epithelial cells (T7) transfected with SARS (N) or (M) DNA, respectively.

To determine whether these DNA vaccines could induce T-cell immune responses in humans as well as in mice, SCID-PBL/hu mice were immunized with these DNA vaccines. PBL from healthy human volunteers were administered i.p. into IL-2 receptor $\gamma$-chaindisrupted NOD-SCID mice [IL-2R(-/-) NOD-SCID]. SCID-PBL/hu mice thus constructed can be used to analyze the human immune response in vivo. The SCID-PBL/hu mice were immunized with SARS (N) DNA or (M) DNA and analyzed for a human T-cell immune response. The M DNA vaccine enhanced CTL activity and proliferation in the presence of $M$ peptide in SCID-PBL/hu mice. Furthermore, the SARS N DNA vaccine induced CTL activity (IFN- $\gamma$ production by recombinant $\mathrm{N}$ protein or $\mathrm{N}$ protein-pulsed autologous $\mathrm{B}$ blast cells) and proliferation of spleen cells in SCID-PBL/hu mice. These results, demonstrate that SARS M and N DNA vaccines induced human CTL and human T-cell proliferative responses.

On the other hand, we have developed SARS DNA vaccines that induce human neutralizing antibodies and human monoclonal antibodies against SARS CoV. Transgenic mice expressing SARS-CoV receptor (angiotensin converting enzyme 2) are also under development. These vaccines are expected to induce immune responses specific for SARS $\mathrm{CoV}$ in human and should provide useful tool for development of protective vaccines.

\section{INTRODUCTION}

The causative agent of severe acute respiratory syndrome (SARS) has been identified as a new type of corona virus, SARS corona virus (SARS-CoV) $)^{1,2,3}$. SARS has infected more than 8400 patients in about 7 months in over 30 countries and caused more than 800 deaths. The deadly epidemic has had significant impacts on many health, social, economic and political aspects. SARS may resurge in the near future. However, no SARS vaccine is currently available for clinical use. Therefore, we have developed novel vaccine candidates against SARS CoV using cDNA constructs encoding the structural antigens; S, M, E, or N protein. In immunized mice, neutralizing antibodies against the virus and T-cell immunity against virus-infected-cells were studied, since these responses play important roles in protection against many virus infections. In particular, CD8 ${ }^{+} \mathrm{CTL}$ plays an important role in $\mathrm{T}$ cell immunity against virus infections and in the eradication of murine and human cancers. ${ }^{4,5}$ In the present study, a type II alveolar epithelial cell clone, T7, was used for 
analyzing precise mechanism of CTL against SARS-CoV membrane antigens, as the SARS-CoV infects alveolar epithelial cell in the lungs. ${ }^{6}$ Furthermore, the SCID-PBL/hu model, which is capable of analyzing in vivo human immune response, was also used because it is a more relevant translational model for human cases. ${ }^{4}$ These vaccines induce human immune responses (neutralizing antibody and CTL) specific for SARS CoV in human and should provide useful tool for development of protective vaccines.

\section{MATERIALS AND METHODS}

Three SARS CoV strains HKU39849 ${ }^{1}$, TW-1, and FFM-1 ${ }^{2}$ and their cDNAs were used. S, M, N, or E cDNA was transferred into pcDNA 3.1(+) vector and pcDNA $3.1(+) /$ vs-His Topo (QIAGEN K K, Tokyo, Japan). These genes were expressed in eukaryotic cells and Escherichia coli. pcDAN 3.1(+) vector, $50 \mu \mathrm{g}$ each, containing SARS $\mathrm{S}, \mathrm{M}, \mathrm{N}$, or E DNA was injected i.m. (M. tibia anterior) into C57BL/6 mice (female, 8 weeks, CLEA Japan Inc, Japan) and BALB/c mice (female, 8 weeks) three times, at an interval of 7 days. Neutralizing antibodies against SARS CoV in the serum from the mice immunized with SARS S, M, N, or E DNA vaccines were assayed using Vero-E6 cell. CTL activity against SARS-CoV was studied using human type II alveolar epithelial cells, T7, expressing SARS antigens. ${ }^{6}$ PBL from healthy human volunteers were administered i.p. into IL-2 receptor $\gamma$-chain-disrupted NOD-SCID mice [IL-2R(-/-) NOD-SCID], and SCID-PBL/hu mice were constructed. ${ }^{4}$ SARS DNA vaccines at $50 \mu \mathrm{g}$ were injected i.m. into the SCID-PBL/hu mice. CTL activity of human CD8-positive lymphocytes in the spleen from SCID-PBL/hu was assessed using IFN- $\gamma$ production and ${ }^{51} \mathrm{Cr}$-release assay ${ }^{4,5}$ Human monoclonal antibodies were produced from B cell hybridoma using P3U1 myeloma cell and spleen cells from human immunoglobulin transchromosomic mice (KM mice).

\section{RESULTS}

Induction of CTL against SARS CoV by SARS (N) DNA and SARS (M) DNA vaccine: Spleen cells from C57BL/6 mice immunized with SARS-S, -M, -N or -E DNA vaccine were cultured with syngeneic T7 lung cells transfected with $\mathrm{S}, \mathrm{M}, \mathrm{N}$, or E cDNA. pcDNA 3.1(+) SARS (N) DNA vaccine induced significantly CTL activity (IFN- $\gamma$ production) against N cDNA transfected T7 cells. Similarly, SARS M DNA vaccine induced SARS antigen M-specific CTL against T7 cells transfected with SARS M DNA.

Augmentation of lymphocyte proliferation specific for SARS CoV antigens by immunization with SARS (M) DNA and SARS (N) DNA vaccine: The proliferation of splenic T cells stimulated by co-culture either with T7 cells transfected with M DNA or SARS M peptide (TW1 M102-116) was strongly augmented by M DNA vaccine (data not shown). SARS N DNA vaccine also induced proliferation of splenic T cells in the presence of recombinant $\mathrm{N}$ protein as well as N DNA-transfected T7 cells. Thus, both SARS N 
DNA vaccine and M DNA vaccine were shown to induce T-cell immune responses against the relevant SARS-CoV antigens.

Induction of neutralizing antibodies against SARS-CoV by immunization with SARS(S) DNA vaccine: The production of neutralizing antibodies against SARS CoV using Vero E6 cells infected with SARS CoV was observed in the serum from BALB/c mice immunized with S DNA vaccine in the presence of adjuvants (MPL+TDM+ALUM) (Table 1).

Table 1. Induction of neutralizing antibody against SARS coronavirus by SARS (S) DNA vaccination of $B A L B / c$ mice.

\begin{tabular}{|c|c|c|c|}
\hline & $\begin{array}{l}\text { Immunization } \\
\text { with }\end{array}$ & Adjuvant & $\begin{array}{l}\text { Neutralizing antibody } \\
\text { against SARS corona virus }\end{array}$ \\
\hline pcDNA $3.1(+)$ & $\begin{array}{l}\text { SARS } \\
\text { HKU-S DNA } \\
\text { Vaccine 50 } \mu \text { g }\end{array}$ & $\begin{array}{l}\text { MPL } \\
\text { TDM } \\
\text { ALUM }\end{array}$ & + \\
\hline \multirow[t]{3}{*}{ pcDNA $3.1(+)$} & $\begin{array}{l}\text { SARS } \\
\text { HKU-S DNA } \\
\text { Vaccine 50 } \mu \mathrm{g}\end{array}$ & - & - \\
\hline & $\begin{array}{l}\text { SARS } \\
\text { TW1-S DNA } \\
\text { Vaccine }\end{array}$ & $\begin{array}{l}\text { MPL } \\
\text { TDM } \\
\text { ALUM }\end{array}$ & + \\
\hline & $\begin{array}{l}\text { SARS } \\
\text { TW1-S DNA }\end{array}$ & - & - \\
\hline
\end{tabular}

SARS M DNA and N DNA vaccines induced human T-cell immune responses (CTL and proliferation) and the production of neutralizing antibodies against SARS-CoV in $S C I D-P B L / h u$ model: The M DNA vaccine enhanced CTL activity and proliferation in the presence of $M$ peptide in SCID-PBL/hu mice. Furthermore, the SARS N DNA vaccine induced CTL activity (IFN production by recombinant $\mathrm{N}$ protein or $\mathrm{N}$ protein-pulsed autologous B blast cells) and proliferation of spleen cells in SCID-PBL/hu mice (Fig. 1). From these results, it was demonstrated that SARS M DNA vaccine and N DNA vaccine induced human CTL and human T-cell proliferative responses. Furthermore, human neutralizing antibodies were induced in SCID-PBL/hu mice vaccinated with SARS S and M DNA (Table 2).

\section{DISCUSSION}

We have demonstrated that SARS (M) DNA and (N) DNA vaccines induce 


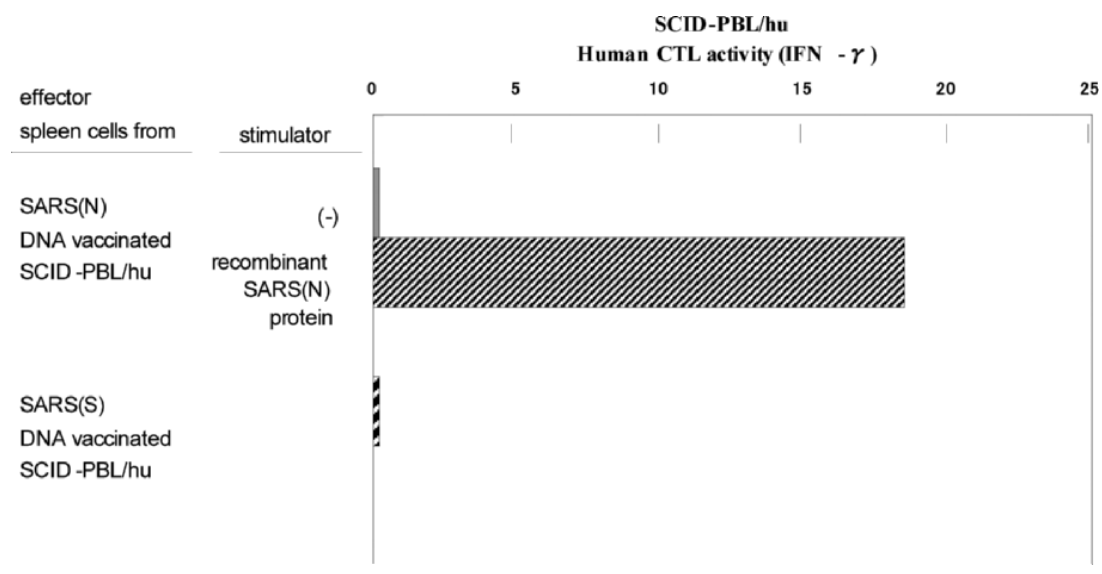

Figure 1. SARS (N) DNA vaccine induces in vivo human CTL against SARS CoV in the SCID-PBL/hu human immune systems. $4 \times 10^{7} \mathrm{PBL}$ from healthy human volunteers were administered i.p. into IL-2R (-/-) NOD-SCID. $1 \times 10^{5}$ spleen cells from SCID-PBL/hu were cultured with $10 \mu \mathrm{g}$ of recombinant SARS $(\mathrm{N})$ protein for $72 \mathrm{hr}$.

Table 2. Induction of human neutralizing antibody against SARS coronavirus in SCID $\mathrm{PBL} / \mathrm{hu}$ mice by SARS DNA vaccinations.

\begin{tabular}{|c|c|c|c|}
\hline M ice & $\operatorname{Immunization}_{\text {with }}$ & Adjuvant & $\begin{array}{l}\text { Neutralizing antibody } \\
\text { Against SARS Corona Virus }\end{array}$ \\
\hline $\begin{array}{l}\text { IL-2R g-chain(-/-) } \\
\text { NOD-SCID PBL/hu } \\
\text { mice }\end{array}$ & $\begin{array}{l}\text { SARS } \\
\text { TW 1-S } \\
\text { SARS (S) DNA }\end{array}$ & $\begin{array}{l}\text { Adenovirus vector } / \\
\text { IL-6DNA+IL-6R DNA+gp 130DNA } \\
+ \\
\text { MPL }\end{array}$ & + \\
\hline $\begin{array}{l}\text { IL-2R g-chain(-/-) } \\
\text { NOD-SCID PBL/hu } \\
\text { mice }\end{array}$ & SARS(M) DNA & $\begin{array}{l}\text { Adenovirus vector/ } \\
\text { IL-6 DNA + IL-6R DNA + gp } 130 \text { DNA }\end{array}$ & + \\
\hline & & - & - \\
\hline
\end{tabular}

$50 \mu \mathrm{g}$ of SARS (S) DNA was immunized three times into SCID mice (IL-2 Receptor $\gamma$-chain-disrupted NOD SCID) at the interval of 7 days.

virus-specific immune responses (CTL and T-cell proliferation) in the mouse system type II lung alveolar T-cell lines to present antigen. ${ }^{6}$ These DNA vaccines induced SARS-CoV-specific CTL and T-cell proliferation in vivo human immune systems using SCID-PBL/hu. Gao et al. showed that an adenovirus-based SARS DNA vaccine encoding S1 polypeptide was capable of inducing neutralizing antibody, while another SARS DNA vaccine encoding $N$ protein generated IFN- $\gamma$ - producing 
T cells in rhesus monkeys. ${ }^{7}$ SARS S DNA vaccines elicit neutralizing antibody responses that generate protective immunity in a mouse model (8). However, its immunogenicity inhumans has yet to be established. Therefore, it is very important to evaluate the efficacy of SARS DNA vaccines in SCID-PBL/hu mice, which is a highly relevant translational model for demonstrating human immune responsiveness. SARS $\mathrm{S}$ DNA and SARS M DNA vaccines capable of inducing human neutralizing antibodies against SARS CoV have been established by our SCID-PBL/hu model. It has been demonstrated that angiotensin- converting enzyme 2 (ACE2) is a functional receptor for the SARS CoV. ${ }^{9}$ A transgenic mouse with human ACE-2 may be useful as an animal model of SARS. Furthermore, ACE-2 transgenic SCID mice should be useful as a human model for preclinical trial for SARS vaccines, for analyzing human immune responses against SARS infection in vivo. The effect of combination immunization with such SARS vaccines and nentralizing antibody-inducing DNA vaccines is now being studied. These DNA vaccines should provide a useful tool for development of protective vaccines.

\section{ACKNOWLEDGMENT}

This study was supported by Grant-in-Aid for science and technology and Grant-in-Aid for Scientific Research on Priority Areas from the Ministry of Education, Culture, Sports, Science and Technology, Japan. This study was also supported by a Health and Labour Science Research Grant from the Ministry of Health, Labour, and Welfare, Japan.

\section{REFERENCES}

1. Peiris JS, Lai ST, Poon LL, et al. SARS study group. Coronavirus as a possible cause of severe acute respiratory syndrome. Lancet. 361:1319-25 (2003).

2. Drosten C, Gunther S, Preiser W, et al. Identification of a novel coronavirus in patients with severe acute respiratory syndrome. $N$ Engl J Med. 348:1967-76 (2003).

3. Peiris JS, Yuen KY, Osterhaus AD, Stohr K. The severe acute respiratory syndrome. $N$ Engl J Med. 349:2431-41 (2003).

4. Tanaka F, Abe M, Akiyoshi T, et al. The anti-human tumor effect and generation of human cytotoxic T cells in SCID mice given human peripheral blood lymphocytes by the in vivo transfer of the Interleukin-6 gene using adenovirus vector. Cancer Res. 57:1335-43 (1997).

5. Okada M, Yoshimura N, Kaieda T, Yamamura Y, Kishimoto T. Establishment and characterization of human T hybrid cells secreting immunoregulatory molecules. Proc Natl Acad Sci U S A. 78:7717-21 (1981).

6. deMello DE, Mahmoud S, Padfield PJ, Hoffmann JW. Generation of an immortal differentiated lung type-II epithelial cell line from the adult $\mathrm{H}-2 \mathrm{~K}(\mathrm{~b})$ tsA58 transgenic mouse. In Vitro Cell Dev Biol Anim. 36:374-82 (2003)

7. Gao W, Tamin A, Soloff A, et al. Effects of a SARS-associated coronavirus vaccine in monkeys. Lancet. 362:1895-6 (2003).

8. Yang ZY, Kong WP, Huang Y, et al. A DNA vaccine induces SARS coronavirus neutralization and protective immunity in mice. Nature. 428:561-4 (2004).

9. Li W, Moore MJ, Vasilieva N, et al. Angiotensin-converting enzyme 2 is a functional receptor for the SARS coronavirus. Nature. 426:450-4 (2003) 